\title{
RESEARCH ON THE INTEGRATION OF HISTORICAL RESOURCES IN WUHU ANCIENT CITY, CHINA
}

\author{
WANG ZHENYU \\ Department of Architecture and Urban Planning, Huazhong University of Science and Technology, China
}

\begin{abstract}
Starting from Wuhu's historical and cultural origin, this research studies the historical status and historical development of the ancient city of Wuhu, as well as the regional culture and folk crafts that remain today. Secondly, in order to study the spatial characteristics of the ancient city of Wuhu, combined with ancient maps and the spatial status quo today, the paper summarizes the ancient city of Wuhu's approximate ellipse urban morphology, the T-shaped street system, the two rivers' converged waterfront environment, etc. Furthermore, aiming at the cultural and historical aspects of the ancient city and its spatial characteristics, the paper makes an historical and cultural resource integration of the ancient city by reconstructing patterns, combing streets, marking highlights, repairing texture, restoring landscapes and other aspects. In order to promote the overall conservation of the ancient city, the old city's renewal and development lays the foundation for the next step.

Keywords: Wuhu, ancient city, historical resources, integration, conservation.
\end{abstract}

\section{INTRODUCTION}

The spatial pattern that the city formed in its evolution is the urban historical heritage and crystallization of building wisdom. The city itself is the materialized form of human civilization, especially the historic city, carrying the long-standing Chinese culture. Today, China's most administrative counties are evolved from the ancient city, and the ancient city which becomes the city's "ring" is a "collective memory" of city life in a specific historical period, as well as a rare urban context (He Yi [1]). Wuhu's "Ten-Li long street" and "ancient city", "old leased territory" left now represent the glory in the history of Wuhu, and are a prime example of Wuhu culture.

Wuhu has a long history and rich cultural resources, and the reputation of Yangtze Rivera's huge port is historically considered the backbone of Anhui province. In the context of today's new urbanization construction, people are paying conservation and the renewal of the ancient city more and more attention, and there is an urgent need to study the ancient city of Wuhu. In this paper, the ancient city of Wuhu, the object of the study, and the ancient town of Wuhu, which was built in the Ming and Qing Dynasties, is studied for the scope of the ancient city of Wuhu's historical and cultural resource integration, conservation and renewal, and I explore the overall conservation planning method of the historical city, including its planning and design, to promote its historical and cultural development, to enhance the characteristics of urban culture and to lay the foundation for the next step - the "ancient city's design guidelines".

\section{CULTURAL ORIGIN}

In ancient China, a "city" is the product of military struggle. Later, because of the involvement of politics, economics and social activities, especially the emergence of the "market", the city has gradually evolved into a modern city. Located in the middle and lower reaches of the Yangtze River, Wuhu is an important city in the southeast of Anhui province. The historical evolution of the ancient city of Wuhu also repeats the process. 


\subsection{Historical environment of the ancient city}

Wuhu ancient city is located in the territory of land and sea, and has an important military position. The ancient city of Wuhu was moved from the south bank of the city of Chuwang during the Three Kingdoms period; that is, it was moved to the green Qingyi River side of the feather mountain highlands, along the Qingyi River from the Yangtze River estuary less than ten miles. Wuhu ranks the left bank of the Yangtze River the "Chuanzhong River of danger", is located in the "Wu head Chu tail", has convenient traffic, geographical advantages, and has repeatedly suffered military chaos throughout history, having experienced more than 50 wars. Wuhu ancient city became the battleground of the Yangtze River Basin's water and land army.

In the era of agriculture as the leading industry, and water transport as the main mode of transport, Wuhu relied on the Yangtze River's golden waterway and along the Qingyi River in southern Anhui's farming area of the vast hinterland, to establish a "trade center" status. During the Ming and Qing Dynasties, Wuhu was an important water transport hub leading to ancient Huizhou in the Yangtze River Basin, and its economy has been further developed. In 1876, Wuhu started port business; the Li Hongzhang family as the founders of the "Wuhu meters City", brought foreign culture and the rapid integration of social and economic aspects of Wuhu. Thus, Wuhu City rapidly expanded, and became the most prosperous trade city of Anhui along the Yangtze River region (WLCCC [2]).

\subsection{Historical context of the ancient city}

During Wuhu's economic rise in the late spring-autumn period, Chu built an area of about 1 ha of military barriers, the Western Han Dynasty set up Wuhu County - Song Dynasty which became a commerce city, and Wuhu had the advantage of the Yangtze River's golden waterway, from the fort to the town of business functions. During the Ming Dynasty, China experienced the ancient city movement, and at the county level cities were built within brick walls; in addition, the rapid development of Wuhu's economy can be attributed to early Ming Nanjing. Qing Wuhu reached the peak of water transport business, as the first of Yangtze River's "four rice cities".

At the end of the Qing Dynasty, the whole of China was opened to trade, and Wuhu, as an important town in the Yangtze River valley, was opened as a treaty port. Its economic and urban buildings achieved "leapfrog development", and the area of the west gate to the Yangtze River became a concession area. With the development of the city, the Ming and Qing Dynasties were no longer interested in the needs of the ancient city, walls were demolished, and the ancient city streets were widened. Following the initial founding of the city for continued development, especially its reform and opening up to trade, and the rapid development of China's economy, the ancient city's many historic houses in the northern, eastern and southern regions of Wuhu were demolished, and the city is constantly being updated (see Fig. 1).

\section{SPATIAL CHARACTERISTICS}

Today's Wuhu City is built on the basis of the ancient city of Wuhu in the Ming and Qing Dynasties (see Fig. 2). The ancient city of Wuhu's ancient city walls marked the city's border; today, although the walls have been demolished and turned into an eastern ring road, Ring Road, the ancient city border is still visible (see Fig. 3). Inside the ancient city, the original street system is still maintained, and important signs are still preserved; the ancient city's pattern is clearly discernible (He Yi [1]). To retain a large number of historical buildings, the ancient city has become the origin of urban development, which is significant. 


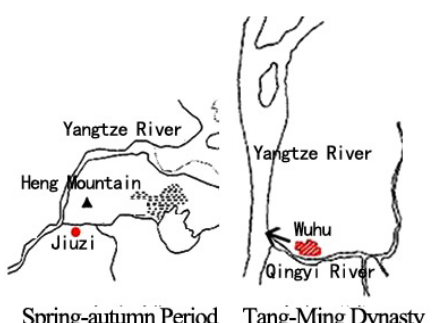

Spring-autumn Period Tang-Ming Dynasty
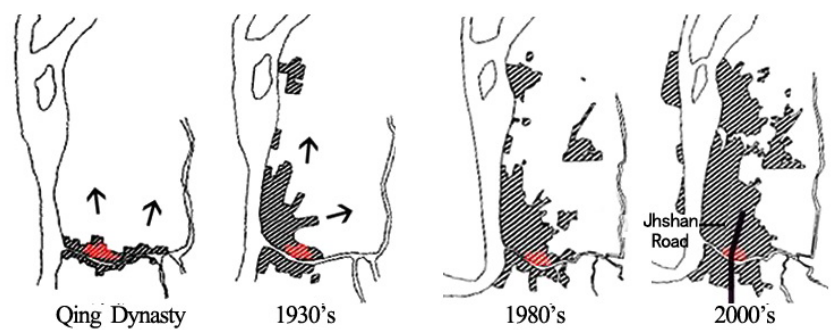

Figure 1: The evolution of Wuhu's urban space.

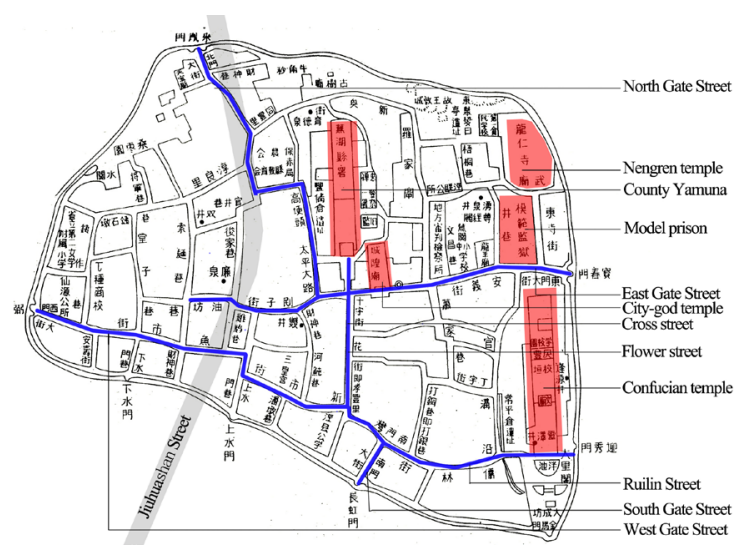

Figure 2: Historic map of Wuhu in the late Qing Dynasty.

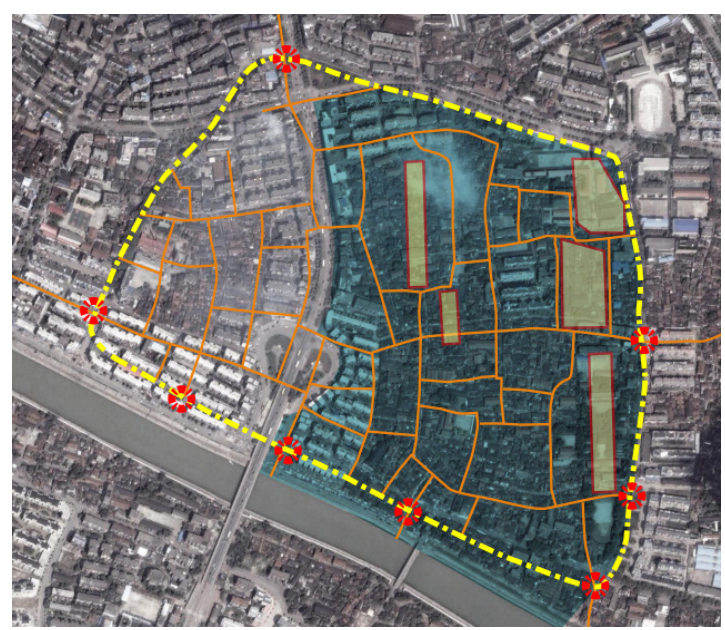

Figure 3: Historic and present superposed map of Wuhu. 


\subsection{Pattern characteristics of the ancient city}

3.1.1 The embraced pattern by mountains and rivers

Wuhu's ancient city site is in accordance with China's "geomantic omen" and Confucian rites thought. The "Second River Interchange" is not only a place of fertile land and abundant water supply, but a place which is very suitable for human life. Thus, the ancients said: "Not see the mountains, look at the water, the real dragon falls at the water together, really points fall at the water". According to the Qing Emperor Kangxi's "Taiping Prefectures Chronicles", Xia Chong's "Rebuild the Mountain Temple Sequence" records the following: "There are three mountains in Daying Sea, is expected to not. Shen Mountain is the originator of the mountains, so have the name, the mountain of aura significantly" (TLCCC [3]). Wuhu on the left for the Jing Mountain, the right is the Zhe Mountain, the base of the bend in front of the flow is Qingyi River, opposite the mountain is the Baima Mountain; the town axis runs from north to south, the terrain is flat with a certain slope, the town is located in the center of the mountain water hold, and is the best place in the environment.

\subsubsection{The city's form of approximate ellipse}

The ancient city was built in the Ming Dynasty. According to Wuhu County Local Chronicles compiled in the years of public China, "Wuhu County built in the Ming Wanli three years, the ancient city in the east of the county thirty kilometers, since Wu Huangwu came into the county, the county abandoned. This county town around seven hundred and thirty-nine feet, high three feet, south of the river said Changhong door, Wang Tao Kun 'built city mind' placed stone in the door of the building, the north has been to reach the North Gate Bridge, called the Laifeng door; there is a moon city" (WLCCC [4]).

By the micro-terrain and water system constraints, the overall shape of the ancient city is approximately oval. County government is in the middle, with Cross Street and Flower Street together constituting the north and south axis of the ancient city. In the Republic of China during the demolition of the wall after the widening of the road around the city, and the Ming and Qing dynasties, compared to the historical map, Wuhu is still part of the Ming and Qing dynasties; to maintain the pattern of the two cities, the walls, gates, and road networks are still faintly discernible, and some of the important traditional buildings still remain. The original city walls have been demolished, the city roads have been opened up, and the gates no longer exist.

\subsection{Texture characteristics of the ancient city}

\subsubsection{T-square streets texture}

The main street of Wuhu ancient city is not entirely in accordance with Chinese ritual thinking's "symmetrical" approach. The vertical axis of the ancient city of the street is very clear, that is, Yamuna, Cross Street, Flower Street, and the turn to the South Gate Street. The horizontal axis street has two south sides of the Liu Xiemen-Rulin Street-New City Street-Fish Street-Simon, East Gate-An Yi Street-Minzi Street, form a "terra-shaped" axis system. The other streets of that block and the main street phase was free to grow state, more "T-shaped", the formation of free street alleys, a typical southern city road network form. Today, the road system in the land is relatively well preserved, and most of the streets still maintain in their original directions, of which half of the streets still maintain the Qing Dynasty Republic of China street scale. 
The carriage- and walking-oriented streets of the ancient city constitute the main road skeleton, the overall streets have retained lots of the traditional street patterns of the ancient city and the scale of the ancient city's streets and alleys; the streets on both sides of the architectural style reflect the ancient city's traditional spatial features, where South Street and Flower Street's aspect ratio lies between 0.5 and 1, the streets are closed and there is no close, compact space, and Rulin Street's aspect ratio lies between 1 and 2.

\subsubsection{Courtyard combined buildings texture}

The ancient city of China is a collection of architectural buildings as a whole, the iconic public buildings and the bottom level of the merchants living in residential buildings shine, forming a city of rich space. Public buildings are usually larger, in the city of its iconic role, forming a city monument. These landmarks have a lot of public buildings like the county Yamuna (government), the exemplary prison, Confucian temple, City-god temple, Nengren temple, and so on. Among them, in the ancient Chinese county, the county Yamun, Confucian temple, and City-god temple play an important component of the composition of the county, representing the traditional Chinese city in the administration, education, clan worship and other major functions. The courtyard combination of these public buildings, like rectangular planes and the axis of symmetry, form the ancient Chinese architectural form of a typical combination. Now, only the main gate of Wuhu Yamuna remains, of the city-god temple only the goddess of the door and the location of the door remains, of the Confucian temple only Dacheng Hall remains, and Nengren temple has completely disappeared. People are still accustomed to worship in front of the Temple in worship, it has become a city faith which cannot be erased.

The ancient city of Huizhou has the characteristics of a small courtyard patio combination model. Pink walls and gray tiles are a prominent impression of Huizhou architecture. The patchwork of the horse wall is not only aesthetically beautiful, but, more importantly, it has a firewall and can block the spread of fire. One of the characteristics of the Huizhou dwellings is the high wall of the deep courtyard; on the one hand it provides a defense against thieves, on the other hand, it ensures displaced people suffering from migrating families get psychological security needs. Another feature of the Huizhou residential area is the deep courtyard as the center of the formation of the courtyard, surrounded by a high-wall enclosure, with almost no view outside to see the tiles, only to narrow the patio lighting, ventilation and communication with the outside world. This kind of patio as the center and the basic form of an enclosed high wall is the focus of attention. Rain falls from the four sides of the roof into the patio, commonly known as "four water Guantang", but also vividly reflects the Huizhou merchants' "fertilizer does not flow outsiders Tian" mentality, which is similar to the Shanxi residential similarities.

\subsection{Landscape characteristics of the ancient city}

\subsubsection{Waterfront environment of two rivers together}

Wuhu lies at the end of Qingyi River, and is the springboard for trade into the Yangtze River that spreads to other places; the Wuhu ancient city is extended along the green Yijiang. "Wuhu ancient city", as the only historical and cultural landscape along the Qingyi River of landscape style, brings great value, and greatly enhanced the heterogeneity of the landscape of the Qingyi River. At the same time, Qingyi Jiang has become an important natural environment of Wuhu ancient city, and not only provides a convenient water transport for the ancient city of Wuhu, but makes the Wuhu city more agile. In the early Ming Dynasty, "Wuhu attached to the river from the mountain, there are many cars, the 
goods are rich, almost same as the state county. Nowadays, inside and outside the city, there are many bazaars, rich products, very lively, to the night is not peaceful". Today, Qingyi River is Wuhu's "Mother River", the number of ships today has been reduced, but the ship tonnage has increased, and it still reflects the historical landscape. The history of the most distinctive engravings in a seat across Qingyi River's Riverside Bridge, Zhongshan Bridge, Flower Bridge, etc., are reflected in the important development of Qingyi River in Wuhu.

\subsubsection{Open space combined with public buildings}

If the traditional building's density is too large, then open space organizations always incorporate the area with public buildings (Pickard [5]). There is a saying in history, "Yamane in front, temple in the north"; public space is the most important area of the ancient city, usually to accommodate a rally or small market. For example, the county before the square has a square axis to become the city's most important open space. This is also the case around the Confucian temple, where the space is rich, the forms are diverse, and it is used as an important and spiritual place for coordinating daily life.

There are few public greenbelt systems in ancient Chinese cities, and public landscapes are the landscape environment. There are city walls out of the ancient city, and the parts of land that are not built inside the city walls may be green spaces. There are many private gardens in the ancient city, including monastery gardens, which can be used for the residents' garden activities, and inside the temple green space is turned into an open space. But in the process of urban development, these spaces are gradually destroyed, and some even become ruins. There is an urgent need to reinstate and build a system for the open space from the overall level, and gradually restore the traditional open spaces that are combined with public buildings.

\section{SYSTEM CONSTRUCTION}

Some urban elements do not usually change or have survivability, such as roads, borders, cities and forms of residence, which constitute the soul of a city, the most eternal part of the city (ICOMOS [6]). That is the city's two-dimensional internal structure, which you can identify using the historical map or even the current map. And I understand the history of urban conservation and renewal, according to its historical prototype, the pattern, texture, landscape and other aspects of the status quo and development needs of historical resources integration design.

\subsection{Pattern reconstruction of the ancient city}

\subsubsection{The form integration of the ancient city}

A historical city has both physical and imaginary forms: walls, kiosks, temples and houses play a real role; streets, markets, open space and other blank space plays a role in the virtual world. This is the element of a strong autonomy, in the development of the city plays an important role in inertia, especially the walls and the axis of the city to control the longterm stable development. The city is composed of interacting and interdependent spatial elements with a certain hierarchy and structural organic whole. Kevin Lynch [7] proposes that these mental maps have five elements - path, node, region, border and sign; the pattern of the ancient city space has an important role in the integration of the ancient city boundary's repair and strengthening of the shaft system.

Today, the ancient city walls of Wuhu no longer exist, but the ancient walls and gates are still living in the memory of the public; I propose to rebuild a closed enclosure as one of 
the historical symbols of the city. Thus, the restoration of today's historical central boundary borders, through the partial reconstruction of the walls and gates and the construction of a park around the park, to rebuild a complete enclosed system, as part of the city's history. Although most of today's buildings have been demolished, but the streets are still preserved, part of the street is still surrounded, the interface of continuous construction. Therefore, in the history of the axis of the street, we trace the history of the ancient city, the most important of which is the county Yamuna, Cross street and Flower street axis, not only to protect the road in the layout, but the history of the street, its pavement, the street scale and space richness should also be consistent with the history of unity (see Fig. 4).

\subsubsection{The spatial structure planning}

The environment of the ancient city area contains deep memory, the overall environment and the spatial form of the ancient city is the primary manifestation of the external appearance of the city, and its overall form has the most important value for the continuation and development of the ancient city. This plan takes full account of the traditional pattern of the ancient city and the historical relics, combined with the modern functional needs, through the planning of the ancient city to form a "three-axis, two, multi-center" spatial planning structure (see Fig. 5).

Three axis: the north and south to the main axis of the "ancient city to visit the spindle" and two east to west main axis "cultural experience axis", "food experience axis". The ancient city to visit the main axis, from the ancient city of the northern end of the same section with the abundance of the door into the traditional food street to the office and the Temple, and then by the flower street, South Gate Bay, South Street until the ancient city of South Gate Qingyi River terminal. The core of the main street area is the core space of the ancient city area, the core space in the north is divided into the "public space" of the county and the "city dome" to reflect the diversity of the public activity space, reflecting the ancient city lots in the history of the cultural characteristics of the southern core space for the South Gate Bay, is the ancient city of commercial prosperity of the logo space.

Two bands: the southern along the Qingyi River "Riverside tourism leisure belt" and the northern ring north of the city "city life belt".

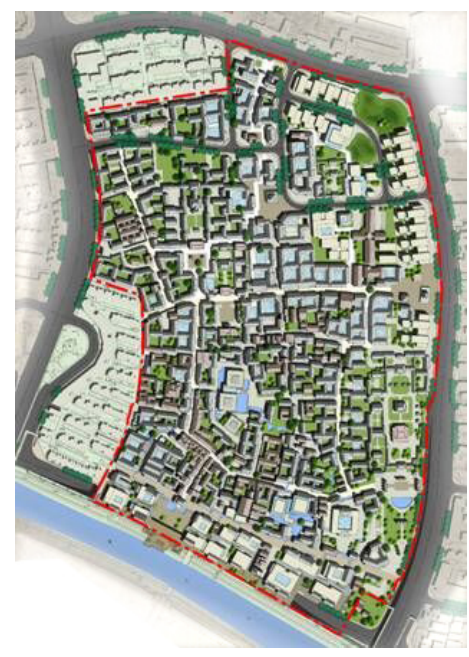

Figure 4: General planning.

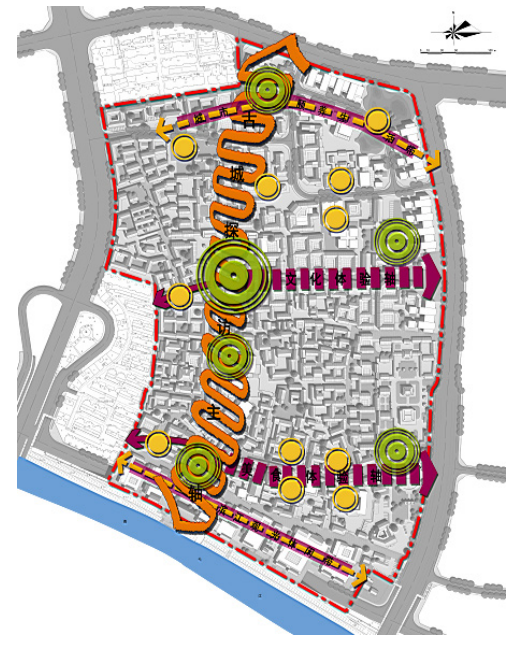

Figure 5: Spatial structure planning. 
Multi-center: that is, by the axis, series form Ya station node center, the North Entrance Center, Bai Square node center, South Gate Plaza node center, East Gate Plaza node center, Confucian temple - Golden Gate Square node center and other space nodes center.

\subsection{Texture repairing of the ancient city}

\subsubsection{Texture repairing of streets}

The whole city is formed by points and lines, and the overall form is the composition of the street, the lane and the network, and the units of the courtyard and the courtyard. Therefore, in order to solve the needs of commercial, transportation and tourism, we can reproduce the traditional commercial street style of the ancient city area, and build a humanized pedestrian network environment, and sort out the aspects from the street and the node. Street combinations should be based on the original building as a basis for reference, as far as it is possible to retain the horizontal structure of the street contours, through the construction interface, forming a rich spatial level, which can be designed as a green, small square, increasing the city's open space, and helping to form a good business/living space.

Riverside Street, Flower Street, South Gate Bay, East Street and other existing key streets are combined so that the original integrity is retained; sort out the Taiping Road, playing Tong Lane, Xiaojia Lane and other retaining lanes and according to the modern behavior model to properly adjust its texture, as far as possible to retain the original location of the roadway, the establishment of a lane-road system, and the land should form a direct circuit with the street; the streets, lanes, get the form of texture to the physical environment, the formation of the ancient city of complete space form. In addition, the height of the ridge line along the street building, the form of the roof, the height and angle of the slope and other aspects of the comprehensive consideration, to shape the level of scattered street skyline, adjust the size of the windows and the entrance, so that commercial space can penetrate, to create greater business vitality in the region (see Fig. 6).

\subsubsection{Texture repairing of buildings}

Urban texture is made up of buildings, and was constituted by the prototype by the living (China courtyard form) at the beginning, but has suffered a lot of alteration and division in the long run. Thus, only a small part of the housing can still remain in the old city of Wuhu. But by analyzing the map and carrying out a detailed investigation of the existing buildings, testing their different structural materials, etc., we can outline the original urban texture, and design according to the law of the formation of the buildings.

In the historical city, the historical relics and public buildings are the hallmarks of the city, and have important social, historical and cultural significance. But these elements of the ancient city of Wuhu are almost destroyed because of the demolition, so it is advised to repair some important buildings containing the county Yamuna, Confucian temple, Citygod Temple and other buildings, recommended in the site, according to historical data to rebuild these historical elements (see Fig. 7).

The courtyard is the basic unit of the ancient city area, which conforms to the spatial texture and terrain features of the street, and has the characteristics of changing form and flexible combination. As the traditional commercial buildings in Wuhu ancient city, the patio courtyard layout type of the ancient city for the prototype, learn from the ancient city before the shop or shop on the store business model mixed layout, and according to the use of functional requirements to adjust the layout of the form. The planning also combined with the needs of the functional format appropriate use of the courtyard plus back and forth hospital and hospital "patio" layout type system (see Fig. 8). 


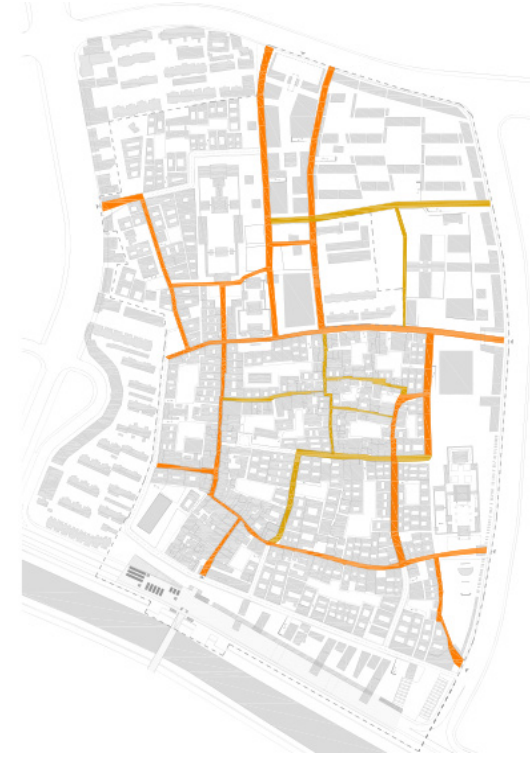

Figure 6: Street repairs.

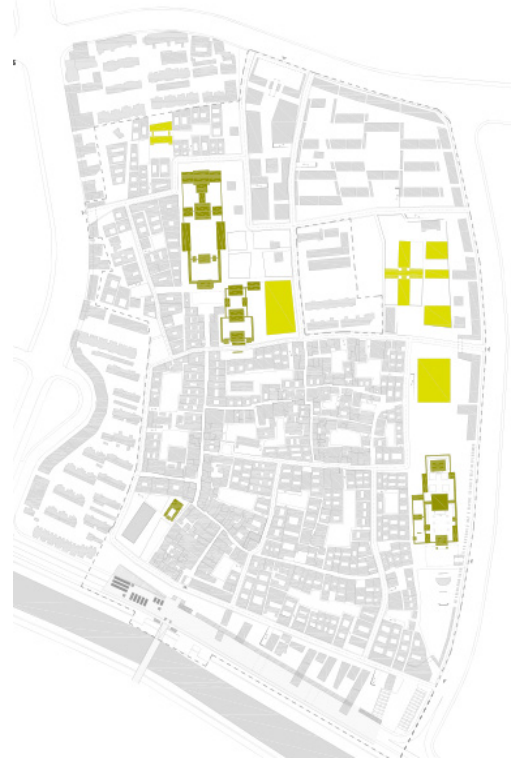

Figure 7: Projection of marks.

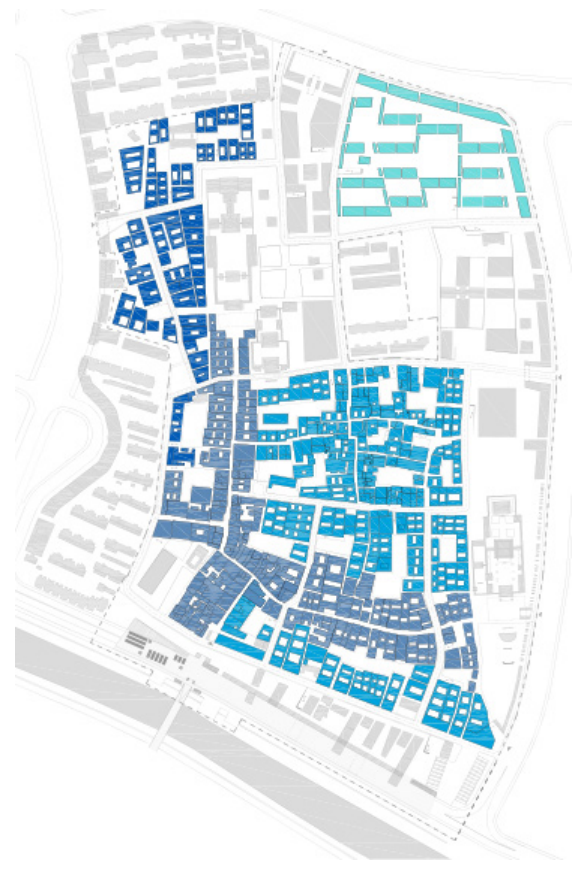

Figure 8: Restoration of dwellings. 


\subsection{Landscape remodeling of the ancient city}

\subsubsection{The construction of the landscape system}

The reshaping of landscape resources is an important aspect of historical resources integration. The historical origins of Wuhu City, "Jiang Dong's First City", reasonable attractions to build and space layout, to build the ancient city of landscape's green space system, can create Wuhu as a "Riverside characteristic tourist city". Taking into account the city in the introverted space too much, the lack of open space characteristics, in combing the streets of the texture at the same time in which to add an open space, such as City-god temple, Confucian temple, North Gate Entrance Square, South Door square and so on, so that the combination of street space, the formation of a complete order, change the rich space experience. In the Confucian temple, the small heaven and other public buildings to the north, the new medium-sized landscaping, the form of Jiangnan traditional gardenbased, planted for the purpose of decoration for the purpose of garden plants.

At the south gate's riverside sightseeing recreation area of the ancient city is the famous Wuhu rice market, which is historically the terminal business district, the source of the ancient city lots, and the accumulation of strong historical and cultural characteristics. On the Qinyi River, an important channel for waterway transport, it is planned to reproduce the prosperity of the pier business district, adhere to the humanist design, entertainment, shopping, bars, high-end dining and art galleries and other modern functional factors into them.

\subsubsection{The reshaping of eight sights of the ancient city}

On the basis of excavating and refining the cultural resources of the ancient city, the concept of "Culture River City" is used to reshape the eight sights of the Ancient City in the whole, thus highlighting the characteristics of urban history, culture and urban tourism (see Fig. 9).

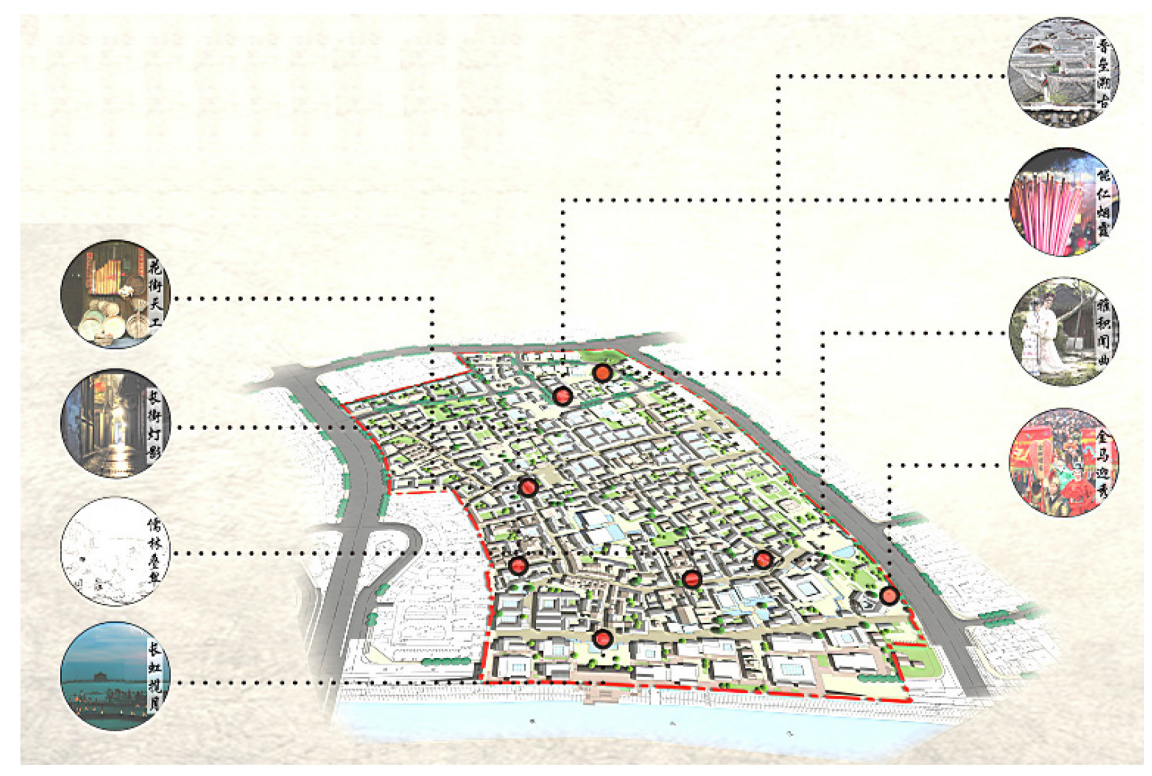

Figure 9: The reshaping of the ancient city of eight sights. 
From the Wuhu County records of the city, we see a "Rampart in memory of Jin dynasty", northeast of feather mountain on the Eastern Jin Dynasty "Wang Dun City"; in the planning, in the northeast corner of the ancient city, there is the design of an open city park, and the "Dream Day Pavilion" is located in the park, both tracing the ancient outline of the city which has a long history, but also conforms to the location of external urban space needs. "Rosy clouds with fog near Nenren temple", taken from textual research on the map of the ancient city, shows the northeast of the construction of the temple, with incense and scenes full of life. "Golden horse greeting gifted youth", from the "Wuhu Xue Gong in the county in the southeast of a promise, south of Kinmen and Matsu River flow in the former" and the ancient city of Jinmen and Matsu of the textual research, in front of the temple, showing the ancient city of "humanistic new" culture Inheritance scene. "Lamp shades of long streets", ten miles long street is the ancient city of connecting the green Yijiang River and the Yangtze River trade skeleton, carrying the ancient city of the past mall downtown trade, in the southwest of the salary street through the traditional street space conservation and modern means of display of the combination of show "ten miles long street" this deeply rooted Wuhu city memory.

"Exquisite craft in Flower street", Wuhu's handicrafts are rich and varied, the history of wood, bamboo Biao device, silver tin production and "Mito three paintings" and other workshops gathered on both sides of Flower street; planning on both sides of the flower street to protect the original workshop, and set up a hundred workshops interactive experience museum, showing the exquisite characteristics of local handicraft culture. "Quietness of scholars' circle in Ruilin street", the history of Rulin Street through the Wuhu Confucian Temple, green trees around the quiet and strong Confucian atmosphere, infected and nurtured a generation of talent; planning to protect the Rulin Street, quiet and quiet street scale, and Set up Wuhu Hall of Fame to show the talent of the city's cultural heritage. "Elegant song come out of Yaji building", Yaji building is famous for "Peony Pavilion" in this creation of Tang Xianzu; planning a string of characteristics of the book bar and the south of the opera theater, through the introduction of special opera performances, strengthen the ancient city of human landscape". The code of "daily visits to the streets of the ancient buildings, night tours of drinking poetry", the poem, combined with the ancient city of the South Gate "Changhong door" stands in the Qingyi River and sets the scene; planning in the south of the plot's riverside sightseeing and leisure area along the river, through the inside and outside, with the two river waters against the background, in the light moonlight shows the beautiful scenery of Wuhu city water.

\section{CONCLUSION}

The spatial environment of the ancient city contains deep memory, the overall environment and spatial form of the ancient city is the primary manifestation of the external appearance of the city, and its overall form has the most important value for the continuation and development of the ancient city. The overall pattern of the ancient city, the street texture, the architectural texture, the landscape elements and so on, to the point line surface form an organic whole; therefore, the ancient city's conservation must be on the basis of historical prototype analysis, combined with the shape of its reconstruction.

Conservation is not the ultimate goal; the conservation of the rest should be abandoned. How the ancient city of historical resources after the integration of the ancient city of how to protect the use of active conservation is the real meaning. We must attach importance to the ancient city of cultural heritage construction and conservation, and find the correct conservation methods in order to advance the ancient city's development. 


\section{ACKNOWLEDGEMENT}

This project was aided by the National Science Foundation: No. 51578256.

\section{REFERENCES}

[1] He Yi, Probe into the theory and practice of four-dimensional city, Wuhan University of Technology, 2012.

[2] Wuhu Local Chronicles Compiling Committee (WLCCC), Wuhu City Local Chronicles. Local Chronicles Press, 2009.

[3] Dangtu Local Chronicles Compiling Committee (TLCCC), Taiping Prefecture Chronicles. Kangxi Years of Qing Dynasty.

[4] Wuhu Local Chronicles Compiling Committee (WLCCC), Wuhu County Local Chronicles. Years of the Republic of China.

[5] Pickard, R., Conservation in the Built Environment, Longman: Harlow, 1996.

[6] ICOMOS, The International Charter for the Conservation and Restoration of Monuments and Sites, 1964.

[7] Lynch, K., The Image of the City, Huaxia Publishing House, 2001. 